\section{"O CHORO DO CAPITÃO": NOTAS SOBRE PERFORMATIVIDADES DE GÊNERO E MASCULINIDADES NO FUTEBOL PROFISSIONAL}

\author{
"EL LLANTO DEL CAPITÁN": NOTAS SOBRE LA PERFORMATIVIDAD DE \\ GENERO Y MASCULINIDADES EN EL FÚTBOL PROFESIONAL
}

"THE CAPTAIN'S CRY": NOTES ON GENDER PERFORMATIVITY AND MASCULINITIES IN PROFESSIONAL FOOTBALL

\section{João Paulo Fernandes Soares*, Ludmila Mourão*, Igor Chagas Monteiro*, Doiara Silva dos Santos*}

\section{Palavras-chave}

Futebol.

Identidade

de gênero.

Masculinidade.

Mídias.
Palabras clave

Fútbol.

Identidad de género.

Masculinidad.

Medios de

comunicación.
Resumo: Este artigo tem como objetivo analisar as construções discursivas midiáticas na web sobre as condutas e o "choro emocionado" do capitão da seleção brasileira masculina de futebol, Thiago Silva, no jogo da Copa do Mundo FIFA 2014 entre Brasil e Chile. Para tal, selecionamos reportagens e comentários de internautas em dois sites esportivos nacionais de elevada audiência no período do evento. As interpretações foram realizadas com base na técnica de análise de conteúdo e aportadas em referenciais dos estudos de gênero e masculinidades pós-estruturalistas. As condutas do atleta na mídia foram associadas a processos de "descontrole" e "despreparo" psicológico, materializados no choro, resultando na "inadequação" à posição de capitão, com consequente perda de status e poder. Os discursos ancoram-se nos processos de normalização das masculinidades e da naturalização de ideais viris e heteronormativos no futebol, em que o "controle" das emoções, a supressão do choro e a heterossexualidade ocupam centralidade.

Resumen: Este artículo tiene como objetivo analizar las construcciones discursivas en la web sobre las conductas y el "llanto emocionado" del capitán de la selección brasileña masculina de fútbol, Thiago Silva, en el juego de la Copa Mundial 2014 entre Brasil y Chile. Con este fin, seleccionamos reportajes y comentarios de internautas en dos webs nacionales de deportes con elevada audiencia en el periodo del evento. Las interpretaciones se basan en la técnica de análisis de contenido y en la referencia de los estudios de género y masculinidades posestructuralistas. Las conductas del atleta se han asociado a procesos de "falta de control" y "falta de preparación" psicológica, materializados en el llanto, lo que resultaría en su inadecuación para la posición de capitán, con la consecuente pérdida de estatus y poder. Los discursos están anclados en los procesos de normalización de las masculinidades y de naturalización de ideales viriles y heteronormativos en el fútbol, donde el "control" de las emociones, la supresión del llanto y la heterosexualidad ocupan lugar central.
Abstract: This article analyzes online media discourse constructions about behavior and the "emotional crying" of Brazilian men's football team captain Thiago Silva during the 2014 FIFA World Cup match between Brazil and Chile. We selected articles and comments published during the event on two national sports websites with high audience. Interpretations were based on content analysis techniques related to gender studies and poststructuralist masculinities. The media associated the athlete's behavior with lack of psychological "control" or "preparation" that materialized as crying. That would be "improper" for a captain's position, with consequent loss of status and power. Those discourses are anchored on processes of normalization of masculinities and naturalization of manly and heteronormative ideals in football, where "control" of emotions, suppression of crying and heterosexuality are key.
* Universidade Federal de Juiz de Fora. Juiz de Fora, MG, Brasil.

E-mail: joaopaulosoaresuffi@gmail.com

Recebido em: 21-03-2016 Aprovado em: 11-05-2016 (c) (1) (8) Licence 


\section{INTRODUÇÃO}

Identificado como prática corporal esportiva amplamente difundida na sociedade brasileira, o futebol se tornou relevante na formação cultural nacional e um campo imprescindível para o entendimento de nossa sociedade, na medida em que há uma histórica identificação da modalidade com as histórias de vida de boa parte dos sujeitos em nossa cultura, a ponto de 0 país ser identificado pelo senso comum como "o país do futebol".

Nesse sentido, o futebol opera nos processos de identificação nacional brasileira e é um veículo para o debate sobre os valores éticos e morais, problemas e relações de poder presentes na sociedade, uma vez que ele reproduz e ressignifica sentidos e significados associados a esses processos sociais (GUEDES, 1998).

Assim, a modalidade motiva uma pluralidade de construções discursivas que perpassam suas dinâmicas e trazem possibilidades de compreendermos mimeticamente uma infinidade de discursos e normatizações culturais, à medida que, segundo Connel e Messerschmidt (2013, p. 246), esportes comerciais como o futebol são foco das "[...] representações midiáticas das masculinidades e, devido a sua popularidade, funcionam como uma renovação contínua dos símbolos hegemônicos das masculinidades e das violências e da homofobia frequentemente presente em meios esportivos".

A partir dessa complexidade discursiva, buscamos refletir, mesmo que de forma limitada e contingente, sobre os modos pelos quais as normas e tecnologias de gênero e as masculinidades operam no "campo esportivo" do futebol, compreendendo essa instituição de saber-poder como relevante na construção e difusão desses enunciados.

Nesse contexto, o objetivo do estudo é analisar as construções discursivas midiáticas na web sobre as condutas e o "choro emocionado" do capitão da seleção brasileira masculina de futebol Thiago Silva, durante a partida entre Brasil e Chile, pela Copa do Mundo FIFA 2014, bem como suas repercussões junto ao público internauta. As perguntas que nortearam essa investigação são: quais significados emergem nos discursos da mídia sobre o choro do capitão Thiago Silva? Que normas de gênero e masculinidades foram veiculadas nesses discursos?

\section{PERCURSO METODOLÓGICO}

A pesquisa de campo foi realizada na web, por compreendermos a relevância dos conteúdos e comunicações construídas nos meios digitais, bem como da capilaridade desses espaços e artefatos culturais na difusão e ressignificação de discursos sobre os corpos, os gêneros e as sexualidades na contemporaneidade (MISKOLCI, 2013; PELÚCIO, 2015).

A análise de produções discursivas midiáticas ${ }^{1}$ implica o reconhecimento de que a cobertura de um evento esportivo como a Copa do Mundo de Futebol permite reconhecer e analisar determinadas construções culturais, mediante a compreensão do que é exposto e "invisibilizado" discursivamente.

Nesse contexto, as reportagens e os comentários acerca da conduta e do choro do capitão Thiago Silva no jogo da Copa do Mundo FIFA 2014, entre Brasil e Chile, foram captadas em dois sites esportivos - www.globoesporte.com e www.espn.uol.com.br - escolhidos profissionais, institucionais e pessoais, além de expectativas e suposições sobre a audiência (HALL, 2003). 
intencionalmente por serem locais de elevada audiência e repercussão no "campo esportivo" nacional na web.

A busca e a identificação das reportagens e dos comentários dos internautas ${ }^{2}$ se deram durante seis dias, compreendidos entre 28 de junho e 3 de julho de 2014 - período que se iniciou com o dia do jogo entre Brasil e Chile, momento em que os fatos ocorreram, e finalizou um dia antes do jogo subsequente na competição, contra a seleção da Colômbia, no dia 4 de julho -, em que foram encontradas sete reportagens com oito comentários nos sites ${ }^{3}$ sobre os fatos ligados à conduta do capitão Thiago Silva, em específico aos momentos de choro do atleta.

A captação desse material empírico se deu mediante pesquisa diária nas páginas dos referidos sites, a partir do delineamento temporal de busca, por todas as reportagens e comentários sobre os fatos objetos de nossa análise.

O processo de análise desses artefatos culturais se deu pela utilização da técnica de categorização discursiva vinculada à análise de conteúdo, em que as categorias foram compreendidas como fragmentos discursivos que agregam núcleos de sentido, evocando significados e fazendo emergir, através de sua repetição na pronunciação, aspectos relevantes das subjetividades dos sujeitos que elaboraram tal discurso (BARDIN, 2011).

Para tanto, o processo de categorização foi realizado através da identificação, agrupamento e análise das categorias presentes e recorrentes nos discursos das reportagens midiáticas e nos comentários de internautas, que foram examinados buscando captar temáticas que evocassem núcleos de sentido e categorias convergentes sobre os fatos elencados.

Nesse contexto, as categorias "descontrole" e "despreparo" foram recorrentes nas reportagens e nos comentários dos internautas e, portanto, apontadas como as motivações para as condutas do capitão Thiago Silva. É a partir dessas categorias empíricas e de seu cotejamento com referenciais dos estudos de gênero e masculinidades pós-estruturalistas que desenvolvemos a estruturação e o nexo argumentativo do artigo.

\section{CENAS INICIAIS: O DRAMA DE UM CAPITÃO NO ESPETÁCULO ESPORTIVO}

O que parecia ser apenas mais uma partida da Copa do Mundo de Futebol masculina, disputada no dia 28 de junho de 2014, assume relevância discursiva ao expor, de forma mimética e agonística, prazeres, angústias, tensões, preconceitos e inúmeras manifestações de sentimentos extremados.

Nessa ocasião, a seleção brasileira masculina de futebol enfrentou a seleção do Chile, pelas oitavas de final da Copa do Mundo de Futebol no Brasil. Após o término do embate, que resultou em empate no tempo regulamentar e na prorrogação, anunciou-se a disputa de pênaltis, trazendo requintes ainda mais dramáticos à partida.

A disputa e, consequentemente, as cobranças de pênaltis são compreendidas como rituais de passagem para os atletas (DAMATTA, 2000; 1994), ou - nos termos de Pierre Bourdieu (2004; 1983) - "rituais de instituição", que se materializam na construção social de

2 Este trabalho respeita a Lei de Direitos Autorais $n^{\circ}$ 9610/98, dando o devido crédito a todas as publicações retiradas dos sites.

3 A maioria das reportagens e comentários foi elaborada por homens, o que evidencia que, no Brasil, a produção e a difusão discursiva midiática sobre o futebol ainda figuram como predominantemente masculina. 
momentos desafiadores em que os sujeitos são levados a demonstrar suas capacidades e habilidades, a fim de serem instituídos de poderes destinados aos vencedores desses desafios.

Tal ritual se inicia com a definição, pela comissão técnica, dos atletas que irão cobrar as penalidades. Nesse momento, a figura do capitão da seleção de futebol, Thiago Silva - que até então, segundo o discurso midiático, havia feito uma "boa partida" -, chama a atenção por sua conduta em campo e por sua recusa em bater um dos pênaltis, como podemos acompanhar nos fragmentos das reportagens abaixo:

Antes da cobrança de pênaltis contra o Chile, uma cena chamou atenção no Mineirão: o capitão da seleção brasileira, Thiago Silva, isolado do restante dos jogadores, fazendo uma prece. $\mathrm{O}$ zagueiro foi criticado nas redes sociais, com muitos comentários dando conta que ele estava abalado emocionalmente (THIAGO..., 2014a).

Bater pênalti é uma grande responsabilidade em casa, e pedi a Deus para não chegar a minha cobrança. Errei dois dos três últimos, e o Felipão me perguntou: "Você pode ser o sexto?". Eu disse que não. Pedi para ficar como último da lista, atrás até do Júlio Cesar. Não estava confiante", disse Thiago Silva (THIAGO..., 2014b).

Diante do exposto, percebe-se que, durante a cobrança de pênaltis, inúmeras vezes o foco das câmeras de TV se voltam para o capitão, que está aparentemente exausto, com as mãos no rosto, cabeça baixa, olhos marejados de lágrimas, corpo curvado e estático, ou posicionando-se com o rosto junto ao gramado, alternando momentos de quietude e de choro copioso, em que se faz necessário ser "acalmado" pela comissão técnica.

A partir dessas cenas iniciais, o capitão Thiago Silva e sua performance começam a ser questionados pelo público em geral, evidenciando que suas condutas geraram "incômodos" por divergirem das representações e significados de gênero e masculinidades amplamente difundidos no futebol masculino, especialmente para os sujeitos que ocupam a posição de capitão da equipe.

Buscamos, pois, analisar as construções discursivas sobre as condutas e o "choro emocionado" do capitão, a partir das categorias empíricas "despreparo" e "descontrole" e das teóricas masculinidades e gênero, que vão dialogar com os processos discriminatórios sofridos pelo atleta.

Nesse sentido e pela centralidade no debate sobre os achados da pesquisa, a categoria masculinidades hegemônicas será utilizada neste estudo no plural e a partir de sua reformulação proposta por Connell e Messerschmidt (2013, p. 250):

[...] as masculinidades não são entidades fixas encarnadas nos corpos ou nos traços da personalidade dos sujeitos; as masculinidades são configurações normativas de práticas que são realizadas nas relações sociais e, dessa forma, podem se diferenciar e serem reformuladas de acordo com as relações de gênero em um cenário social particular.

Nota-se que o conceito aponta para a não essencialização e a pluralização de possibilidades das manifestações das masculinidades em uma determinada cultura; no entanto, e paralelamente, há a construção de masculinidades que serão instituídas e privilegiadas pelas normas de gênero e sexualidade vigentes, através de contínuos processos de normalização 4 dos corpos e condutas.

4 Normalizar significa eleger arbitrariamente as identidades inteligíveis culturalmente, seus atributos e condutas, de forma que as demais identidades possam ser contrapostas e hierarquizadas através de um processo comparativo [...]. A identidade normal é naturalizada, "desejável" e "única" (SILVA, 2009 apud GRESPAN; GOELLNER, 2014, p. 1273). 
Abre-se, assim, um "mosaico de significados" de gêneros e masculinidades, que vão das masculinidades hegemônicas viris às masculinidades abjetas"; em outras palavras, os sujeitos que se aproximam desses modelos hegemônicos idealizados e normalizados de masculinidades gozam de processos privilegiados de apropriação de poder e inúmeras possibilidades e oportunidades na cultura. Paralelamente, aqueles sujeitos que fissuram com suas condutas tais modelos experimentam inúmeras violências físicas e simbólicas ${ }^{6}$, que têm como objetivo adequá-los aos ideários hegemônicos de masculinidade e feminilidade (BENTO, 2014; SILVA; GOMES, 2013).

Inseridos na cultura brasileira, os sujeitos são marcados pela expectativa de que, como "homens de verdade", deem vazão aos seus desejos, mas sem perder 0 controle. A lógica acionada para a expressão ou a afirmação dessa masculinidade é beber muito, mas sem perder o domínio sobre si mesmo; a de comer bastante, mas sem passar mal; a de fazer muito sexo, mas sem deixar que isso intervenha ou atrapalhe sua vida profissional e familiar [...]. Conformar-se às masculinidades anteriormente descritas prova-se um exercício difícil e que gera constante tensão psíquica (MISKOLCl, 2013, p. 319).

Nesses longos e ininterruptos processos de significação e disputas, as instituições contemporâneas produtoras de saberes e poderes ocupam centralidade nos modos de subjetivação dessas idealizações de masculinidades nos sujeitos, na medida em que seus postulados discursivos enunciam "verdades" sobre os corpos e suas condutas "adequados" e "viáveis" culturalmente (LOURO, 2013; FOUCAULT, 2011a).

A instituição esportiva assume - em conjunto com outras instituições de saber-poder como escola, família, religião, grupos de sociabilidade e os movimentos de juventude, além dos bares, brincadeiras e brinquedos infantis - lugar de destaque nos processos históricos de normalização e naturalização dos corpos, dos gêneros, das masculinidades e das sexualidades (DORNELLES, 2014).

Assim, no contexto específico do futebol, tal teia de significados generificada materializase em condutas viris ${ }^{7}$ ligadas às modalidades, como agressividade controlada, controle da dor, protagonismo nas competições, robustez corporal evidenciada nos formatos dos corpos, força, agilidade, técnicas corporais adequadas ao desempenho esportivo, superação dos oponentes, liderança, controle das emoções, supressão do choro, a heterossexualidade compulsória ${ }^{8}$ e a heteronormatividade ${ }^{9}$.

$\mathrm{Na}$ juventude, as habilidades corporais se tornam um indicador primeiro de masculinidade, conforme vemos no esporte. Essa é uma forma chave de ligação entre masculinidade e a heterossexualidade na cultura ocidental, com prestígio

\footnotetext{
50 abjeto "polui", "contagia", deve ser evitado; [...] não é outra coisa senão a perturbadora "matéria fora do lugar". Assim, muitos corpos e comportamentos foram instituídos como "fora do lugar", na ilegitimidade (FIGARI; DÍAS-BENÍTEZ, 2009, p. 23).

6 Grespan e Goellner (2014) e Anjos (2015) expõem os processos discriminatórios sofridos por atletas que tensionaram e "subverteram" normas de gênero e sexualidade - Fallon Fox no MMA e Michael no Voleibol - em que as violências simbólicas buscaram, em última instância, readequar esses corpos às normas do sistema sexo - gênero - desejo.

7 Para mais sobre os processos históricos de constituição dos esportes como lócus privilegiado para a difusão e subjetivação de condutas associadas à virilidade, ver Vigarello (2013).

80 conceito de heterossexualidade compulsória, elaborado por Adrienne Rich e apropriado por Judith Butler, diz respeito ao "modelo discursivo/epistemológico hegemônico da inteligibilidade de gênero, o qual presume que, para os corpos serem coerentes e fazer sentido (masculino expressa macho, feminino expressa fêmea), é necessário haver um sexo estável, expresso por um gênero estável, que é definido oposicional e hierarquicamente por meio da prática compulsória da heterossexualidade" (BUTLER, 2003, p. 216).

90 conceito de heteronormatividade, criado em 1991 por Michael Warner, busca dar conta de uma nova ordem social, que diz respeito ao "ordenamento cultural que exige que todos, heterossexuais ou não, organizem suas vidas conforme o modelo heterossexual, familiar e reprodutivo. Com isso, a heterossexualidade não é apenas uma "orientação sexual", mas um modelo político que organiza as vidas dos sujeitos" (COLLING; NOGUEIRA, 2015, p.178).
} 
dado aos meninos com parcerias heterossexuais e o aprendizado sexual imaginado como exploração e conquista (CONNEL; MESSERSCHMIDT, 2013, p. 269).

Fica evidenciado que tais normas têm, nas experiências esportivas dos sujeitos ${ }^{10}$, momentos privilegiados de difusão e subjetivação. Comumente, grupos familiares matriculam seus filhos em "escolinhas" esportivas para que estes incorporem valores e condutas ligadas aos ideais viris, os quais serão solicitados em suas relações sociais de forma mais intensa à medida que sua idade cronológica avança.

Dessa forma, o futebol - devido a sua ampla difusão e relevância cultural na sociedade brasileira - assume centralidade por congregar e apresentar a possibilidade desses aprendizados, que serão, em última instância, "úteis" na vida social desses sujeitos (KNIJNIK; MACHADO, 2008).

\section{4“BOYS DON'T CRY” - OU A CONSTRUÇÃO DAS MASCULINIDADES NORMALIZADAS}

A repercussão midiática das condutas do capitão da seleção masculina de futebol Thiago Silva nos traz pontos de reflexão sobre os significados de gênero e masculinidades que circulam culturalmente e que são constantemente subjetivados, ressignificados e difundidos pelos sujeitos em suas relações sociais, inclusive no web espaço.

Aquelas condutas, em específico os momentos de choro, demonstraram tensionar as normas de gênero e foram trazidas pelos discursos midiáticos como divergentes do que se espera do capitão da seleção brasileira masculina de futebol, na medida em que o choro é imputado às meninas e mulheres na cultura brasileira e "negado" aos homens, que deverão aprender a suprimi-lo e a resguardá-lo ao espaço privado, longe dos olhares dos espectadores do espetáculo esportivo e dos adversários, a fim de não serem colocados na condição de "despreparados" e "descontrolados".

Nesse sentido, os comentários do público internauta corroboram as representações das masculinidades hegemônicas viris, como podemos notar a seguir:

Isso não é um concurso de Miss... Não se pede uma atitude machista do capitão, mas sim de liderança, de passar segurança, de manter-se firme quando 0 desespero se espalha [...]. Choro de emoção é bonito! 0 choro de desespero, igual ao do Thiago Silva, foi a cena lamentável da necessidade de outro capitão. (SYLVIO FROES, sic).

Ele tá jogando bem, mas não pode pipocar e cair naquele choro daquela maneira. E depois sentar na bola, de costas para gol, sozinho e longe do grupo enquanto estava todo mundo ali se arrebentando. Isso não é postura de capitão. Esse papinho de "ele estava orando" não me convence. Ele estava é pipocando. (MALU LOPES, sic).

[...] Ele pedir pra não bater (pênalti) sendo capitão acho inadmissível e decepcionante. Evidencia todo o desequilíbrio emocional do time. Aliás, achei chororô demais pra quem tinha acabado de passar só de um Chile nas oitavas. (CARLOS MUCURY, sic).

O núcleo de sentido em torno da categoria empírica "descontrole" enuncia a ausência de seu oposto: o "controle", evidenciando a cobrança pelo público por "condutas viris" ligadas

10 Um dos elementos importantes na construção da ideia de masculinidade são as marcas corpóreas a serem exibidas: cicatrizes, cortes, arranhões, tatuagens, mutilações. [...]. São as demonstrações concretas da valentia, da luta, do desempenho (JARDIM, 1995 apud MELO; VAZ, 2008, p. 130). 
à liderança e ao enfrentamento das adversidades durante o embate esportivo. No entanto, abre-se outra possibilidade analítica nos discursos, que nos remetem à reflexão sobre as ritualizações em torno do choro dos atletas.

Percebe-se, a partir desses discursos, que o choro no futebol é ritualizado. Há momentos em que ele é permitido e até esperado, como nas vitórias e derrotas, nas graves lesões e entrevistas, geralmente quando o atleta rememora sua trajetória de vida, a superação de possíveis problemas no processo de ascensão na carreira de atleta; em outros momentos, o choro deverá ser interditado, a fim de não ser confundido com "descontrole", "covardia", "medo" ou qualquer conduta que "abale" os significados viris atribuídos aos atletas, como nos confrontos corporais com outros atletas e demais dinâmicas da modalidade e nos momentos decisivos das partidas - como nas cobranças de pênaltis.

Na reportagem abaixo, em que foi utilizada uma fala do ex-capitão da seleção brasileira de futebol Cafu, evidenciam-se tais diferenciações ritualísticas do choro no futebol nessa partida em específico:

[...] 0 choro do Júlio César é extremamente aceitável. Foi um momento de explosão e botou para fora todo sentimento de alegria dele. Fora disso, é chorar menos, entrar em campo mordendo todo mundo, como diz o meu filho, com sangue nos olhos, para jogar. A seleção tem que esquecer o choro e pensar exclusivamente em jogar futebol. ${ }^{11}$

Embora formas diferenciadas de manifestação do choro em que haveria a permissão ao "choro de alegria" fiquem evidentes, percebe-se a ampla interdição do "choro em excesso" ou do "choro de desespero", sob a alegação de que tais condutas são contraditórias com as dinâmicas do futebol, em que se deve "morder" e jogar com "sangue nos olhos" - expressões utilizadas para expor as condutas dos atletas "raçudos", "bravos" e "destemidos", tipos idealizados no imaginário do futebol masculino, sobretudo para os que ocupam a posição de capitão da equipe.

Essas produções discursivas remontam à essencialização dos corpos, dos gêneros e das masculinidades, em que há algo de viril nos homens que faltaria ou seria atenuado nas mulheres, para as quais seriam permitidas a exposição das emoções, a "fragilidade" e "docilidade" nos gestos e condutas, e o choro, como forma de negociação com a realidade social. Dessa forma, a choro dissidente apresenta-se como distanciamento do ideal regulatório das masculinidades hegemônicas viris e representa para os homens uma perigosa aproximação à associação com os significados culturalmente normatizados como sendo expressões de feminilidade.

Tais construções partem de uma visão binária dos gêneros, apoiada em uma teia discursiva de saberes biológicos e genéticos, que remonta à difusão do sistema cultural normativo sexo-gênero-desejo, que diz respeito à associação discursiva direta de um "sexo biológico" (macho ou fêmea), geralmente pronunciado pelo discurso médico, a um gênero (masculino ou feminino), que fica evidente no processo de construção de feminilidade e masculinidade normalizada, e uma sexualidade heterossexual compulsória relegada aos sujeitos (BUTLER, 2000; 2003).

Assim, ao debatermos a segunda categoria empírica, "despreparo", é necessário refletir sobre os modos como se alcança o "preparo", que se materializaria nas condutas "adequadas" nas dinâmicas do futebol.

11 Capitão do penta avalia que time precisa de mais razão e menos emoção em campo. Disponível em: <http://gazetaweb.globo.com/portal/noticiaold.php?c=372436\&e=3> 
Nesse sentido, localizaremos tais categorias nas tramas das construções dos gêneros em nossa cultura, em que os processos educativos generificados são subjetivados incessantemente na instituição esportiva, nesse caso no futebol, e devem ser priorizados através dos treinamentos "físicos" e "psicológicos", que realizam inúmeras ingerências corporais, embora com resistências pelos sujeitos.

\section{TREINAMENTOS E PERFORMATIVIDADES DE GÊNERO NAS TRAMAS DO FUTEBOL}

Os gêneros são incorporações de infindáveis discursos que visam, através de suas tramas de saberes e poderes, conformar os corpos mediante atos performativos ${ }^{12}$, que são reiterados, repetitivos e citacionais, visando, em última instância, subjetivar e inscrever nos corpos formas inteligíveis e "adequadas" de ser homem e ser mulher em uma determinada cultura; no entanto, tensionamentos e dissidências fazem parte dessas dinâmicas e ensejam as subversões de inúmeros padrões culturais (BUTLER, 2000; 2003).

Assim, o choro do capitão Thiago Silva apresenta-se como ato performativo dissidente e traz reflexões sobre a pluralização das masculinidades no futebol. Ao expressar suas emoções nas dinâmicas daquela partida em específico, o atleta, mesmo sendo legitimado como tecnicamente "adequado" a tal posição, sofre interdições e discriminações. Estas se referenciam na categoria "despreparo", que seria, em última instância, uma limitação nos "treinamentos psicológicos" disponibilizados aos atletas, em específico a Thiago Silva, e a uma "inadequação" pessoal ao posto de capitão.

Nesse sentido, no "campo esportivo", os treinamentos serão aqui compreendidos como tecnologias de gênero ${ }^{13}$ que - através da realização reiterada e repetitiva de atos, movimentos e condutas ligados às modalidades - buscam subjetivar performativamente ideais normalizados de masculinidades e feminilidades nos sujeitos que adentram essa instituição; em outras palavras, ao incentivar o controle das emoções, da dor e a supressão do choro durante as sessões de treinamento de forma reiterada, tais condutas podem ser subjetivadas e naturalizadas pelos sujeitos, a ponto de, em momentos posteriores, não ser necessária a intervenção dos(as) treinadores(as) nesses processos.

Ao se afirmar que é preciso ter "raça", "força", "determinação" e "vontade" para vencer uma partida ou um campeonato, selecionam-se sentimentos e condutas que serão priorizados e aceitos, enquanto outros - como a "indolência", a "fraqueza" e a "falta de vigor" nas condutas dos atletas - serão interditados. De forma sutil, corpos estão sendo preparados para atuar de forma viril na disputa esportiva.

Cabe pontuar que, nesses processos de subjetivação/normalização dos corpos, há a interseção com outras instituições produtoras de saberes, como o "campo da Psicologia", em sua vertente ligada aos esportes.

Em nosso material empírico, foram localizadas três reportagens que fizeram circular a temática do "despreparo" psicológico dos atletas da seleção brasileira de futebol naquele

12 A teoria da performatividade busca refletir sobre os mecanismos de inscrição corporal e naturalização discursiva dos gêneros e das sexualidades, através de atos repetitivos, reiterados e citacionais ligados às experiências sociais dos sujeitos em uma determinada cultura e tempo histórico (BUTLER, 2000; 2002a).

13 Ao se apropriar do conceito Foucaultiano de técnica, Preciado (2014, p.154) expõe que "as técnicas se apresentam como um conjunto de dispositivos complexos de poder e de saber que integra os instrumentos e os textos, os discursos e os regimes do corpo, as leis e as regras para a maximização da vida, os prazeres do corpo e a regulação dos enunciados de verdade". Assim, tais ingerências discursivas podem ser notadas nas dinâmicas realizadas pelos sujeitos na instituição esportiva, materializadas nos treinamentos e sem seus processos e normatização corporal. 
momento em específico do campeonato, em que se destacam as condutas do capitão Thiago Silva. Segundo uma dessas narrativas midiáticas, o dia após a partida entre Brasil e Chile foi dedicado a consultas dos jogadores com a psicóloga esportiva da seleção brasileira de futebol, conforme se evidencia na reportagem abaixo:

O estado emocional dos jogadores é o tema do momento na Granja Comary. A comissão técnica está preocupada, e a psicóloga do grupo, Regina Brandão, foi chamada para uma conversa com os atletas. 0 encontro será realizado no C.T. da equipe brasileira antes do treino da tarde. [...] 0 capitão da Seleção, Thiago Silva, teve seu estado emocional contestado e deve passar por consulta com a profissional [...]. (BALTAR; SOUZA; CORREIA, 2014).

Nesse contexto, caberia à psicologia esportiva restabelecer o "controle emocional" perdido pela equipe, em especial pelo capitão Thiago Silva. Nota-se que os mecanismos utilizados pelo discurso midiático, ao expor as emoções dos atletas, giram em torno das categorias "descontrole", "despreparo" emocional e, em última instância, "fraqueza" no embate esportivo. Em outras palavras, caberia o restabelecimento do "status viril" abalado pelo choro e pelas emoções demonstradas durante a atuação da equipe.

Assim, a conduta dos atletas da seleção brasileira - em especial o "despreparo" psicológico do capitão Thiago Silva - ocupa centralidade:

\begin{abstract}
A preocupação é tamanha que a psicóloga Regina Brandão foi convocada a retornar à Granja Comary. [...] 0 capitão é uma das maiores preocupações da comissão. Sua postura antes dos pênaltis chamou atenção. Ele ficou sentado sobre uma bola, isolado, com expressão facial absolutamente abatida. Depois da classificação, o zagueiro admitiu que exagerou ao externar sua preocupação, mas ressaltou que isso não prejudicou seu desempenho em campo. [...]. A esperança da comissão técnica é ver um grupo menos abalado na próxima partida. (LOZETTI, 2014).
\end{abstract}

Transparece a representação de que as "preparações psicológicas" dos atletas no futebol são compreendidas como ações que buscariam proporcionar a incorporação de condutas ligadas ao "controle das emoções", à "contenção dos ímpetos", à resistência às provocações dos adversários e aos insultos das torcidas, bem como determinar em que momento o choro poderá ser externado.

Que significados tornam a conduta do capitão Thiago Silva dissidente e passível de tamanha repercussão? Ao se isolar, em vez de se unir à equipe; ao permanecer em silêncio, quando se esperava que gesticulasse e bradasse gritos de "força": "vamos vencer", "garra"; e ao chorar, em vez de conter suas emoções, os incômodos surgem na medida em que se evidenciam a instabilidade e o caráter construído dessas normas de gênero em meio à "magnitude espetacularizada" meticulosamente produzida em torno dessa competição e da partida em específico. Essas condutas, que poderiam demonstrar o alto grau de tensão gerado por essa partida decisiva, causam "incômodos", ao divergirem das representações das masculinidades hegemônicas viris construídas e associadas a um atleta da seleção de futebol.

Ainda sobre as "obrigações" que emergem da posição de capitão, as idealizações desse sujeito líder, corajoso, "frio" e viril ficam evidenciadas no excerto da reportagem a seguir:

Havia uma figura de capitão com uma personalidade muito forte [...] que é aquele cara que peita o juiz, que dá entrevista, que dá a cara a tapa, que vem na frente. O Thiago Silva é um dos capitães mais retraídos, mais calados que já se viu. Ele 
não tem aquela personalidade que a gente acha que um capitão encarna [...]. Nos causa estranheza, pois estamos acostumados a conviver com aquele tipo de capitão [...]. (THIAGO..., 2014c).

Tais discursos fazem emergir algumas normas de gêneros e masculinidades presentes no futebol, fartamente reproduzidas, em que se ressaltam as condutas de outros atletas/ capitães, convergentes com os ideais das masculinidades hegemônicas viris. Tais sujeitos demonstram, de acordo com as narrativas acima, estar mais "bem preparados psicologicamente" para a posição de capitão, o que não ocorreria com o atleta Thiago Silva, que, a partir de seu choro, foi arbitrariamente classificado como "retraído", "calado", "inseguro" e portador de uma "personalidade fraca" - ou seja, inadequado ao posto.

Assim, aquele "tipo ideal viril" idealizado nos discursos ocuparia centralidade em um projeto esportivo que se pretenda "vitorioso", na medida em que ele, além de liderar e motivar seus companheiros, seria responsável por difundir os valores arbitrariamente elencados como "adequados" à modalidade esportiva em questão, policiando, inscrevendo e subjetivando tais discursos e condutas nos integrantes de sua equipe.

\section{CONSIDERAÇÕES FINAIS}

Ao abordar os desdobramentos discursivos das condutas e do choro do capitão Thiago Silva na web, buscamos analisar alguns mecanismos desses processos de normalização dos gêneros e das masculinidades. Um deles reside nos intentos de deslegitimar a competência em liderar a equipe demonstrada pelo atleta, a partir das categorias discursivas "descontrole" e "despreparo". Em outras palavras: um atleta que ocupa a posição de capitão e chora no desenvolvimento de uma partida de futebol não congregaria os "atributos viris" inerentes ao posto.

Nota-se que, por trás desses enunciados, tece-se uma teia discursiva naturalizada dos gêneros e das masculinidades evidenciada nos significados culturais ligados à virilidade na performance esportiva, em que o controle das emoções e a supressão do choro assumem centralidade.

Dessa forma, ao chorar publicamente em diversos momentos do espetáculo esportivo, o capitão perde status e poder nas dinâmicas da modalidade, abrindo margem para a desnaturalização subversiva dos significados de gênero, que devem ser constantemente restabelecidos através de treinamentos diversos, inclusive das preparações psicológicas.

Ao término melancólico da participação da equipe brasileira no mundial, derrotada pela seleção da Alemanha, seguiu-se a demissão do técnico, assim como a retirada da braçadeira de capitão de Thiago Silva. Tais atos representam, em última instância, a busca por um restabelecimento das normas de gênero no espetáculo esportivo do futebol, mediante a busca de um "líder viril", que possa demonstrar ter sido "melhor" subjetivado nas condutas ligadas às masculinidades hegemônicas viris, podendo, assim, difundir tais normas aos integrantes da equipe, em uma constante vigilância dos gêneros e das masculinidades desses atletas.

Enfim, cabe pontuar que nos interessam a desnaturalização, as dissidências e as transgressões, no processo de escrutínio dos arbitrários culturais de gênero que cerceiam subjetividades e punem aqueles sujeitos "inadequados" às normas, fortalecendo as 
necessidades de se expor, através de outros estudos, agências e resistências dos sujeitos nas tramas discursivas contemporâneas e as possibilidades das manifestações de uma pluralidade de masculinidades no "campo esportivo" e na sociedade.

\section{REFERÊNCIAS}

ANJOS, Luiza Aguiar dos. Vôlei masculino é pra homem: representações do homossexual e do torcedor a partir de um episódio de homofobia. Movimento, v. 21, n. 1, p. 1-24, jan./mar. 2015.

BALTAR, Marcelo; SOUZA, Richard; CORREIA, Thiago. Psicóloga da Seleção chega à Granja para reunião com os jogadores: questão emocional domina noticiário da equipe após classificação contra o Chile. 1 jun. 2014. Disponível em: <http://globoesporte.globo.com/futebol/selecao-brasileira/ noticia/2014/07/psicologa-da-selecao-chega-granja-para-reuniao-com-os-jogadores.html>. Acesso em: 12 mar. 2016.

BARDIN, Laurence. Análise de conteúdo. 6. ed. Lisboa: Edições 70, 2011.

BENTO, Berenice. A reinvenção do corpo: sexualidade e gênero na experiência transexual. 2. ed. Natal: EDUFRN, 2014.

BOURDIEU, Pierre. A juventude é apenas uma palavra. In: BOURDIEU, P. Questões de sociologia. Rio de Janeiro: Marco Zero, 1983. p. 112-121.

BOURDIEU, Pierre. Ritos de instituição e instâncias de legitimação. In: BOURDIEU, Pierre. Questões de sociologia e comunicação. São Paulo: Annablume, 2004. p. 95-126.

BUTLER, Judith. Corpos que pesam: sobre os limites discursivos do sexo. In: LOURO, Guacira Lopes. 0 corpo educado: pedagogias da sexualidade. Belo Horizonte: Autêntica, 2000. p. 151-198.

BUTLER, Judith. Como os corpos se tornam matéria. Revista Estudos Feministas, v. 10, n. 1, p.155$167,2002 b$.

BUTLER, Judith. Cuerpos que importan: sobre los limites materiales y discursivos del "sexo". Buenos Aires: Paidós, 2002a.

BUTLER, Judith. Problemas de gênero: feminismo e subversão da identidade. Rio de Janeiro: Civilização Brasileira, 2003.

COLLING, Leandro; NOGUEIRA, Gilmaro. Relacionados mas diferentes: sobre os conceitos de homofobia, heterossexualidade compulsória e heteronormativdade. In: RODRIGUES, Alexsandro; DALLAPICULA, Catarina; FERREIRA, Sérgio Rodrigo da Silva. (Org.). Transposições: lugares e fronteiras em sexualidade e educação. Vitória: EDUFES, 2015. p. 171-184.

CONNEL, Robert W.; MESSERSCHMIDT, James W. Masculinidade hegemônica: repensando 0 conceito. Estudos Feministas, v. 21, n. 1, p. 241-282, jan./abr. 2013.

DAMATTA, Roberto. Antropologia do óbvio: notas sobre o significado social do futebol brasileiro.

Revista USP, n. 2, p.10-17, 1994.

DAMATTA, Roberto. Individualidade e liminaridade: considerações sobre os ritos de passagem e a modernidade. Mana, v. 6, n. 1, p.7-29, 2000.

DORNELLES, Priscila Gomes. Corpo, gênero e práticas corporais esportivas: diálogos iniciais a partir da teoria queer. In: FERRARI, Anderson et al. (Org.). Corpo, gênero e sexualidade. Lavras: UFLA, 2014. p. 139-158. 
DORNELLES, Priscila Gomes. Gênero e sexualidade na educação física escolar: notas sobre a normalização dos corpos no interior baiano. In: DORNELES, Priscila Gomes; WENETZ, Ileana; SCHWENGBER, Maria Simone Vione. (Org.). Educação física e gênero: desafios educacionais. ljuí: Ed. Unijuí, 2013. p. 215-238.

DORNELLES, Priscila Gomes; POCAHY, Fernando Altair. Prendam suas bezerras que o meu garrote está solto! Interseccionando gênero, sexualidade e lugar nos modos de subjetivação regionais.

Educar em Revista, n. 1, p. 117-133, 2014.

FIGARI, Carlos Eduardo; DÍAZ-BENÍTEZ, María Elvira. Sexualidades que importam: entre a perversão e a dissidência. In: DÍAZ-BENITEZ, María Elvira; FIGARI, Carlos Eduardo. (Org.). Prazeres dissidentes. Rio de Janeiro: Garamond, 2009. p. 21-30.

FOUCAULT, Michel. A ordem do discurso: aula inaugural no Collège de France pronunciada em 2 de dezembro de 1970. 21. ed. São Paulo: Loyola, 2011b.

FOUCAULT, Michel. História da sexualidade I: a vontade de saber. Rio de Janeiro: Edições Graal, 2011a.

FOUCAULT, Michel. Microfísica do poder. Rio de Janeiro: Graal, 1992.

FOUCAULT, Michel. Vigiar e punir: nascimento da prisão. Petrópolis: Vozes, 1987.

GRESPAN, Carla Lisboa; GOELLNER, Silvana Vilodre. Fallon Fox: um corpo queer no octógono. Movimento, v. 20, n. 4, p. 1265-1282, out./dez. 2014.

GROSSI, Miriam Pilar. Masculinidade: uma revisão teórica. Antropologia em primeira mão, n. 1, p. 4-37, 1995.

GUEDES, Simoni Lahud. 0 Brasil no campo de futebol: estudos antropológicos sobre os significados do futebol brasileiro. Niterói: EDUFF, 1998.

HALL, Stuart. Codificação/decodificação. In: HALL, Stuart. Da diáspora: identidade e mediações culturais. Belo Horizonte: Ed. UFMG, 2003. p. 387-404.

KNIJNIK, Jorge Dorfman; MACHADO, Afonso Antônio. Bailarinos do esporte: notas sobre novas masculinidades em campo. In: ROMERO, Elaine; PEREIRA, Erik Giuseppe B. (Org.). 0 universo do corpo: masculinidades e feminilidades. Rio de Janeiro: Shape, 2008. p. 137-152.

LOURO, Guacira Lopes. Um corpo estranho: ensaios sobre sexualidade e teoria queer. 2. ed. Belo Horizonte: Autêntica, 2013.

LOZETTI, Alexandre. Lado emocional preocupa e pode pesar até na escalação da Seleção:

Felipão e a comissão técnica estão preocupados com a reação dos jogadores à pressão pelo título. Paulinho, fortalecido, pode ganhar mais uma chance. Disponível em: <http://globoesporte.globo.com/ futebol/selecao-brasileira/noticia/2014/07/lado-emocional-preocupa-e-pode-pesar-ate-na-escalacaoda-selecao.html>. Acesso em: 12 mar. 2016.

MELO, Victor Andrade de; VAZ, Alexandre Fernandez. Cinema, corpo, boxe: reflexões sobre suas relações e notas sobre a questão da construção da masculinidade. In: ROMERO, Elaine; PEREIRA, Erik Giuseppe B. (Org.). 0 universo do corpo: masculinidades e feminilidades. Rio de Janeiro: Shape, 2008. p. 117-136.

MISKOLCI, Richard. Machos e brothers: uma etnografia sobre o armário em relações homoeróticas masculinas criadas on line. Revista Estudos Feministas, v. 21, n. 1, p. 301-324, jan./abr. 2013.

PELÚCIO, Larissa. O amor em tempos de aplicativos: notas afetivas e metodológicas sobre pesquisas com mídias digitais. In: PELÚCIO, Larissa; PAIT, Heloisa; SABATINE, Thiago. (Org.). No 
emaranhado da rede: gênero, sexualidade e mídia - desafios teóricos e metodológicos do presente. São Paulo: Annablume, 2015. p. 81-108.

POCAHY, Fernando Altair. Interseccionalidade: uma prática-teorização feminista possível na era pósgênero? In: DORNELES, Priscila Gomes; WENETZ, lleana; SCHWENGBER, Maria Simone Vione. (Org.). Educação física e gênero: desafios educacionais. ljuí: Ed. Unijuí, 2013. p. 69-87.

PRECIADO, Beatriz. Manifesto contrassexual. São Paulo: n-1 edições, 2014.

SILVA, Paula; GOMES, Paula Botelho. Masculinidades como singularidades múltiplas: uma proposta de análise das masculinidades no desporto. In: DORNELES, Priscila Gomes; WENETZ, Ileana; SCHWENGBER, Maria Simone Vione (Org.). Educação física e gênero: desafios educacionais. ljuí: Ed. Unijuí, 2013. p. 45-68.

THIAGO Silva pediu para ser o último cobrador na disputa de pênaltis. Globoesporte.com, 28 jun. 2014b. Disponível em: <http://globoesporte.globo.com/futebol/copa-do-mundo/noticia/2014/06/thiagosilva-pediu-para-ser-o-ultimo-cobrador-na-disputa-de-penaltis.html>. Acesso em: 10 mar. 2016.

THIAGO Silva, sobre isolamento antes dos pênaltis: minha oração. Globoesporte.com, 29 jun., 2014a. Disponível em: <http://globoesporte.globo.com/futebol/selecao-brasileira/noticia/2014/06/ thiago-silva-queria-um-momento-meu-para-fazer-minha-oracao.html>. Acesso em: 10 mar. 2016.

THIAGO Silva, um capitão 'diferente' que não precisa ser um 'homem de ferro'. Globoesporte.com , 29 jun. 2014c. Disponível em: <http://espn.uol.com.br/video/422100 thiago-silva-um-capitao-diferenteque-nao-precisa-ser-um-homem-de-ferro>. Acesso em: 10 mar. 2016.

VIGARELLO, Georges. Virilidades esportivas. In: CORBIN, Alain; COURTINE, Jean-Jacques; VIGARELLO, Georges. História da virilidade 3: a virilidade em crise? Séculos XX-XXI. Petrópolis: Vozes, 2013. p. 269-301. 


\section{Apoio:}

Universidade Federal de Juiz de Fora (UFJF) 